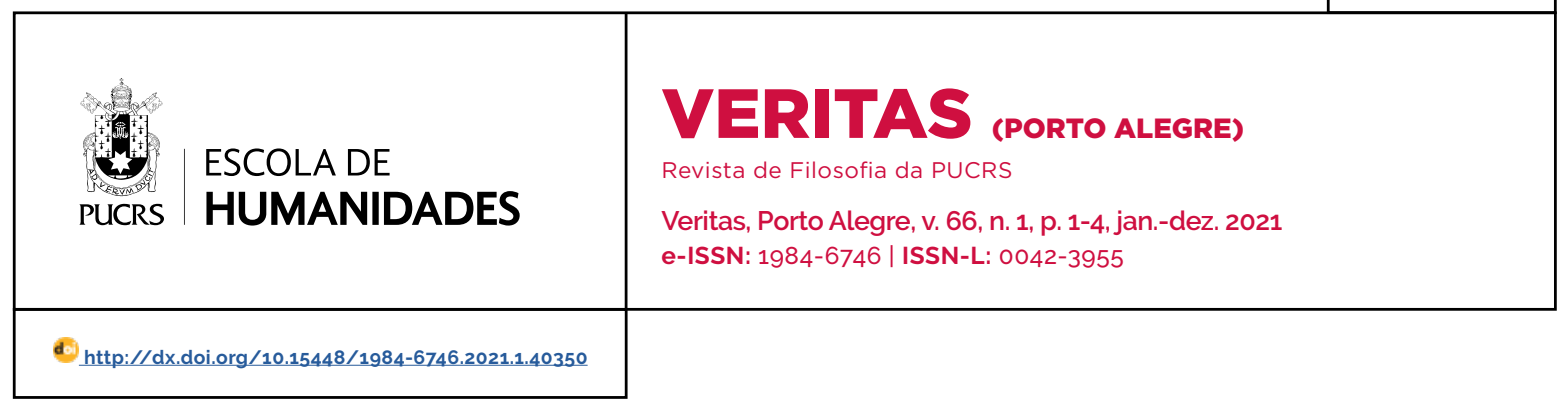

RESENHA

\title{
Sobre a construção de uma impossibilidade
}

On constructing an impossibility

Sobre la construcción de una imposibilidad

\section{Judikael Castelo \\ Branco $^{1}$ \\ orcid.org/0000-0002-4551-2531 judikael.castelo@mail.uft.edu}

Recebido em: 13 mar. 2021. Aprovado em: 22 jun. 2021 Publicado em: 23 jul. 2021.
CANHADA, Júlio. O discurso e a história. A filosofia no Brasil no século XIX. São Paulo: Loyola, 2020. 270 p.

É muito provável que, hoje, os discursos sobre filosofia francesa, alemã ou norte-americana, não causem nenhum estranhamento nos interessados em filosofia, o que talvez não seja o caso diante da expressão "filosofia do Brasil". No entanto, é sempre bom não olvidar que até Descartes e Montaigne, a expressão "filosofia francesa" era inteiramente vazia de sentido, que só depois do Sturm und Drang, o "pensamento alemão" passou a significar algo de fato, e, finalmente, que há pouco mais de cem anos, mais precisamente antes do pragmatismo de Peirce, era impossivel falar de "filosofia norte-americana". Isso nos lembra que, como gostava de dizer Eric Weil, a filosofia é essencialmente histórica (o que podemos interpretar de muitíssimas formas). Se, por um lado, essa compreensão dos termos sustenta as pesquisas de historiografia filosófica, por outro, ela abre um universo de questões próprias ao filósofo que se ocupa com a história da filosofia, como demonstrou também Lorenz Puntel.

O livro de Júlio Canhada leva a sério essas considerações e procura, no século XIX, as raízes da filosofia no Brasil. Grosso modo, o escrito se orienta pelas questões que abrem o prefácio de Marilena Chauí: primeiro, "se há uma história da filosofia no Brasil", depois, e mais fundamentalmente, "se existe filosofia no Brasil". O constrangimento em torno dessas questões não é estranho a quem se interessa pelo tema, sobretudo se considerarmos que, entre nós, outras "atividades do espírito" já superaram, há muito, indagações dessa natureza. Com efeito, limitando-nos apenas a alguns exemplos mais celebrados, podemos dizer que antropologia, sociologia, pedagogia e economia pensadas no Brasil e a partir do Brasil, já produziram os seus "clássicos", hoje reconhecidos também fora das nossas fronteiras e lidos em diferentes línguas. Claramente deixamos noutro patamar o reconhecimento da nossa literatura. Diante desse quadro, só nos resta concluir que a situação da filosofia é totalmente outra. 
No que respeita à filosofia do século XIX, Canhada sintetiza a consideração geral noutro texto recente e com estes termos:

A produção filosófica brasileira pré-universitária foi, por bastante tempo, avaliada segundo um senso-comum fruto de uma longa historiografia da filosofia no Brasil. De acordo com esse senso-comum, tal produção filosófica, sobretudo do século XIX, estaria marcada por várias ausências: ausência de rigor, uma vez que os autores que se pretenderam filósofos teriam trilhado o inseguro caminho do autodidatismo, ingenuidade na pretensão de estarem aptos a dialogar com grandes autores da história da filosofia; vacuidade e efemeridade de suas propostas filosóficas, dada a ausência de tradição filosófica no Brasil; importação cega de ideias estrangeiras, de modo a apenas repeti-las sem compreenderem sua origem, o que resultaria numa sequência disparatada de modismos (CANHADA, 2021, p. 169).

Para compreender essa realidade, o autor retoma a produção filosófica brasileira em um exercício de pensamento que se desdobra entre o confronto com a nossa historiografia filosófica e a leitura estrutural de textos concentrados na segunda metade do século XIX. Na prática, embora o recorte proposto para o enquadramento das questões seja um periodo específico, o livro se divide em duas partes de extensões desiguais, relativamente autônomas, mas, em essência, igualmente fundamentais à tese que o autor apresenta de modo mais explícito no último capítulo.

No que concerne ao que tomamos aqui como primeira parte, concentrada no capítulo "A construção de uma impossibilidade: histórias da filosofia do Brasil", o autor se dá à reavaliação da historiografia da filosofia brasileira procurando a origem e as razões que sustentam a opinião geral segundo a qual a nossa produção filosófica seria essencialmente falha, isto é, marcada, já na sua substância, por uma "série de ausências". Para tanto, o livro revisa a formação da filosofia universitária e profissional no Brasil reconhecendo a importância do estabelecimento do curso de Filosofia na Universidade de São Paulo (USP) em torno de nomes como Étienne Borne e Jean Maugüé, enquanto salienta alguns traços capitais dessa mesma filosofia, a saber, a centralidade conferida nela ao papel do comentador de tex- tos e o interdito do posto de filósofo. De certa forma, essas características decorrem, como concordam outros estudiosos, da apropriação do método de leitura estrutural formulado por Martial Gueroult e Victor Goldschmidt. Fica evidente na leitura, como um dos resultados dos trabalhos do "departamento francês", o papel central a ser ocupado pelo estudo da história da filosofia. Sobre isso, Canhada traz as palavras de Maugüé, para quem "a filosofia começa com o conhecimento dos clássicos" (CANHADA, 2020, p. 27), o que não apenas traça um "caminho" para ingressar na filosofia, antes manifesta uma determinada compreensão do que sejam a sua natureza e a sua tarefa, e, por conseguinte, define um perfil para o filósofo. Daí a exclusão da filosofia brasileira pré-universitária de toda e qualquer leitura estrutural.

A nosso ver - destacando um dos pressupostos fundamentais sobre os quais Canhada parece sustentar as próprias interpretações - o que está em questão é a consideração da filosofia brasileira pré-universitária sem levar em conta aspectos propriamente metafilosóficos essências à compreensão dos esforços dos autores do século abordado, a saber, a concepção da natureza da filosofia, do papel do social do filósofo e, por último, a relação da filosofia com outros saberes, como a Medicina e o Direito.

Nesse mesmo sentido, o autor repassa a "ressalva" tão característica da nossa historiografia filosófica, tomando como objeto de análise os trabalhos de Sílvio Romero, Leonel Franca, Joao Cruz Costa, Antônio Paim e Paulo Arantes. Sublinhando o contexto e o caráter próprio de cada autor, Júlio Canhada reconhece em todos eles o recurso à desqualificação do objeto tratado, ainda que de modos distintos. Haveria na obra desses estudiosos de nossa filosofia, uma tendência a identificar e "colocar em seu devido lugar" pensadores que se pretenderam filósofos, mas indignos de ocupar esse posto. O procedimento seria precisamente o resgate para a norma do que seria uma filosofia correta, desqualificando, nisso, os textos dos escritores brasileiros anteriores à institucionalização dos estudos de 
filosofia no Brasil. Como acenamos, os caminhos são distintos, embora os resultados sejam idênticos: Franca destaca a falta de originalidade e de autonomia bem como os prejuizos do autodidatismo; Cruz Costa, o apego à Europa; Paim, além de salientar as "ausências em toda parte", reitera a comparação com a Europa; Arantes, reforça o contraste entre as filosofias feitas antes e depois da USP. É Sílvio Romero que merece consideração particular, porquanto é o único dos autores expostos no primeiro capítulo a retornar como tema no restante da obra. Com efeito, Romero não apenas figurará como expoente da Escola de Recife, mas será retomado ainda no capítulo fundamental - aquele que, ao fim e ao cabo, explicitará a perspectiva própria e mais original de Júlio Canhada - "História das temporalidades".

A segunda parte é formada pelo recorte histórico proposto e compreende, no que respeita à cronologia, textos que se estendem entre os anos de 1846, com os escritos de Antônio Pedro de Figueiredo, publicados em O Progresso, e o fim da década de 1880, com atenção à obra de Tobias Barreto. No entanto, a abordagem não é meramente cronológica, antes se orienta de forma sistemática na qual o periodo tratado é lido a partir e em torno dos escritos filosóficos de Gonçalves de Magalhães. Duas razões justificam a centralidade do autor de Factos do espirito humano. Em primeiro lugar, Gonçalves de Magalhães é tomado como uma primeira resposta inteiramente elaborada à polarização de posições que caracteriza o período estudado. Com efeito, Canhada marca muito fortemente, a cada passo e autor, a alternância própria do pensamento filosófico brasileiro entre materialismo e sensualismo de um lado, e idealismo e espiritualismo de outro; embora reconheça, acertadamente, que o posicionamento dos pensadores brasileiros diante desses modelos não esgota as determinações presentes em cada perspectiva filosófica. Em segundo lugar, em um expediente menos comum na nossa historiografia filosófica, o livro toma seriamente a dupla pretensão de Gonçalves de Magalhães, postura que de certo modo caracteriza o desenvolvimento da filosofia no século XIX, a saber, o esforço em tratar todas as grandes questões filosóficas sem, no entanto, qualquer pretensão de criar um novo sistema. Em uma palavra, Canhada vê em Gonçalves de Magalhães um autor inovador e não sistemático, o que se torna patente quando compara a sua obra filosófica aos compêndios de Monte Alverne, Pedro Autran de Malta Albuquerque, Moraes e Valle e Moraes Torres. O efeito imediato da comparação é o reconhecimento de um autor que, conscientemente, não quis se limitar às suas leituras, mas se pôs a discutir os pontos controversos em função da expansão da própria opinião sem receio de se afastar dos seus mestres ou de propor novas teorias. Estariamos, portanto, diante da "construção de uma voz autoral marcada por certa independência em relação aos procedimentos escolares de compilação e apreensão das matérias" (CANHADA, 2020, p. 108).

O livro reporta o desenvolvimento de uma "voz autoral minima" repassando os escritos de Pedro Figueiredo, Eduardo Ferreira França e de Tobias Barreto. Em todos esses autores, há de se notar não só o posicionamento peculiar a cada um diante da oposição entre materialismo e espiritualismo, mas se torna absolutamente imprescindivel perceber também a compreensão compartilhada da necessidade de se pensar o Brasil como nação. Esse esforço exige uma nova relação com o passado, quer dizer, uma releitura do século XVIII. O resultado é a oposição dos pensadores brasileiros à cronologia como único procedimento historiográfico. De novo, é Gonçalves de Magalhaes que melhor sintetiza a exigência de uma ressignificação do passado ao reconhecer que "toca ao nosso século $[X I X]$ restaurar as ruinas e reparar as faltas dos passados séculos" (CANHADA, 2020, p. 231). Logo, fica patente que a fundação de uma filosofia nacional - como busca Magalhães - se insere na fundação do Brasil como nação, na qual se põe também a criação de uma literatura brasileira, na qual o autor de Suspiros poéticos e saudades tem lugar de destaque inquestionável. Na prática, isso representa uma ressignificação da relação da nova identidade nacional com as peças constitutivas da sua formação. 
Para Canhada - e para nós o autor o comprova de forma mais do que suficiente, inclusive pelo uso de uma vasta documentação -, todos esses elementos destoam das constantes afirmações da nossa historiografia que desqualificam a filosofia brasileira pré-universitária. O argumento final, que em mais de um aspecto completa as observações que abrem o volume, o sucesso dessa opinião se assenta em parte nos resultados dos trabalhos de Silvio Romero, mais precisamente na desconsideração do fato de que Romero revê a filosofia nacional a partir de uma posição filosófica específica, sem qualquer pretensão de objetividade ou de neutralidade, antes o contrário, toma os autores estudados em confronto com a sua própria grade classificatória e os percebe como adversários a superar.

Nesse sentido, embora não seja objetivo do livro, cabe aos interessados pelo tema reconsiderar a questão de uma autêntica filosofia nacional sem evidentemente renunciar às conquistas próprias da institucionalização da filosofia universitária. O volume recente de trabalhos consagrados à filosofia brasileira parece apontar para um novo momento da compreensão do fazer filosófico no Brasil, o que não significa que já tenhamos de fato explicitado segundo um discurso conceitual e rigoroso a visão de mundo que se formou a partir dos momentos constitutivos da nossa experiência como nação independente. Porém, o não voltar as costas ao Brasil é com certeza o primeiro passo para isso. O livro de Júlio Canhada é prova de que pensar a produção filosófica brasileira não é apenas viável, mas necessário.

\section{Referências}

CANHADA, Júlio. O discurso e a história. A filosofia no Brasil no século XIX. São Paulo: Loyola, 2020. 270 p.

CANHADA, Júlio. Como aprender a ser filósofo no Brasil no século XIX: Instituições, compêndios, caminhos do saber. Argumentos, Fortaleza, v. 13, n. 25, p. 168-184, 2021.

\section{Judikael Castelo Branco}

Doutor em Filosofia pela Universidade Federal do Ceará (UFC), em Fortaleza, CE, Brasil; e pela Université de Lille, França. Professor da Universidade Federal do Tocantins (UFT), em Palmas, TO, Brasil, junto ao curso de Licenciatura em Filosofia, ao Mestrado Profissional em Filosofia (PROF-FILO/UFT) e ao Mestrado Acadêmico em Filosofia da Universidade Estadual Vale do Acaraú (MAF/UVA). Atualmente, desenvolve pesquisas nas áreas de Ética e Filosofia política, com especial interesse pelo pensamento de Eric Weil e Hannah Arendt. Membro do GT "Eric Weil e a compreensão do nosso tempo" da ANPOF.

\section{Endereço para correspondência}

Judikael Castelo Branco

Universidade Federal do Tocantins

Câmpus de Palmas

Av. NS 15, Quadra 109 Norte, Plano Diretor Norte

Bloco Bala II, Sala 20

77001-090

Palmas, TO, Brasil

Os textos deste artigo foram revisados pela Poá Comunicação e submetidos para validação do autor antes da publicação. 